\title{
LAS ARTICULACIONES SEMÁNTTICAS DEL TEXTO LITERARIO
}

1. En la ponencia presentada en el Coloquio internacional de poética de Varsovia, hace ahora veinte años, decía Roman Jakobson que

a pesar de ciertas formaciones fronterizas, que constituyen una transición entre dos dominios, existe en la lengua una diferencia muy neta entre dos clases de conceptos -conceptos materiales y conceptos relacionales-- o, en términos más técnicos, entre el nivel léxico y el nivel gramatical de la lengua. ${ }^{1}$

En efecto, las partes del discurso no sólo constituyen categorías intrínsecas del código lingüístico, sino que reflejan -para decirlo con Edward Sapir-. "no tanto nuestra capacidad intuitiva para analizar la realidad, cuanto nuestra aptitud para construir esa realidad conforme a diversos modelos formales".2 Así, el carácter prescriptivo de los conceptos gramaticales plantea un problema ciertamente complejo: el de las relaciones entre la función referencial o cognoscitiva de los enunciados verbales y las "ficciones lingüísticas" que, al decir de Jeremy Bentham, deben exclusivamente al lenguaje "su imposible $y$, sin embargo, indispensable existencia".

¿Puede dudarse - se preguntaba Jakobson- del verdadero carácter significativo de los conceptos gramaticales? ¿No les atribuimos acaso un efectivo estatuto de verosimilitud? Desde cierto punto de vista -el de los gramáticos atentos exclusivamente a los aspectos formales no semánticos de los datos lingüísticos - podría sostenerse que las modificaciones que puedan introducirse en el nivel estrictamente "relacional" de un enunciado no provocarán ningún cambio en la

1 Roman Jakobson, "Poésie de la grammaire et grammaire de la poésie", en Questions de poétique, París, Seuil, 1973 ; pp. 219 y ss.

2 Cit., por Jakobson, loc. cit., p. 220. 
"sustancia" concreta, esto es, en las entidades extralingüísticas a las que el discurso hace referencia. Si nos ceñimos, pues, a ese marco "relacional", la alteración del orden de los componentes de un enunciado (por ejemplo "A rige a $B$ " reescrito como " $B$ rige a $A$ ")", no entraña ninguna modificación sustancial de los signata $\mathrm{A}$ y $\mathrm{B}$, sino únicamente de las funciones gramaticales de sus signantia.

Sin embargo, las partes del discurso ́los sujetos, los objetos, las acciones), al tiempo que constituyen invariantes semióticas, entidacles formales de un determinado sistema de signos, clesignan los comportamientos de una realidad concreta que, como recordaba Jakobson, pueden ser analizados de modo muy diverso por diferentes formas léxicas y gramaticales: en términos de actores y de acciones $y$, dentro de ellas, como cosas y como propiedades. De suerte, pues, que la lengua no sólo permite analizar la realidad con arreglo a sus códigos o convenciones semióticas particulares, sino que la existencia de tales códigos puede clar pie a la construcción de una realidad "autónoma" (que quizá sería mejor Ilamar "textual") cuyo soporte inmediato es la Jengua misma y cuyo carácter "ficticio" depende menos del conocimiento que el hablante tenga del mundo real que de su capacidad para comprender, reproducir o transformar el "mundo", en cuanto éste sea asumido como el efecto de las representaciones lingüístico-ideológicas que le han sido asignadas por una determinada comunidad cultural.

La poesía, entendida ahora como una propiedad distintiva de cierta clase de textos $\rightarrow$ no nos importe por el momento el carácter efectivo o asignado de dicha propiedades, o.diremos provisionalmente que es, una especie de "ficción lingüística" en la cual las entidades formales de un sistema semiótico son asumidas como estrictamente solidarias con las sustancias concretas representadas por su intermedio o, dicho de otro modo, como si la estructuración semiótica de la realidad, elaborada de conformidad con los modelos de la lengua ( $y$, por supuesto, con los textos paradigmáticos de una cultura) fuese en un todo equivalente a la estructura de la sustancia real, con independencia del estatuto que otros sistemas semióticos ( $\mathrm{v}$. gr. científicos) pue- 
dan atribuir a las mismas sustancias. Podría afirmarse, consecuentemente, que un texto es "autónomo" o "dependiente" respecto de la realidad referida en la medida que la representación semántica de ésta sea convencionalmente formalizada como una entidad homóloga (i. e. correlativa) o como una entidad interpretante (i. e. sustitutiva).

Tendremos que volver sobre este arduo problema y su problemática formulación. Por el momento, es aún necesario que nos detengamos en el aludido ensayo de Jakobson, puesto que en él se afirma que es en aquellos textos que, conforme a la tradición de los formalistas rusos, llamamos "autónomos" donde "se hace perfectamente evidente que los conceptos gramaticales $[\ldots]$ encuentran sus más amplias posibilidades de aplicación", y ello -además-por cuanto que la poesía es "la manifestación más formalizada del lenguaje".

Ciertamente, y ateniéndonos a los postulados jakobsonianos, la recurrencia de las "figuras gramaticales", fónicas y léxicas, constituyen diferentes manifestaciones del paralelismo, "principio constitutivo de la obra poética" que el propio Jakobson definió como el resultado de proyectar el principio de equivalencia del eje de la selección sobre la combinación, esto es, como consecuencia de construir el mensaje verbal con arreglo simultáneo a dos jerarquías u órdenes diferentes: el paradigma y el sintagma. De ahí que, como afirma el mismo Jakobson, "en poesía toda semejanza perceptible de sonidos sea evaluada con relación a la semejanza y/o desemejanza del significado" y que -añadiremos nosotros- se establezca una equivalencia entre la "sustancia" referida $y$ la formalización lingüistica de dicha sustancia $o$, si se prefiere decirlo diversamente, una correlación homológica entre la forma y la sustancia del contenido de un determinado proceso semiótico.

2. En numerosos trabajos, Jakobson dedicó muy particular atención al parallelismus membrorum, recurso retórico que, según su decir, pone de resalto "la idea que se hace el locutor acerca de las equivalencias gramaticales" y que, junto con la clase de licencias poéticas que caen dentro del 
paralelismo, puede proporcionarnos las claves para un estudio sistemático de la interacción de los niveles fónico, morfológico-sintáctico y léxico en los textos poéticos. Como se recorclará, el maestro ruso ha sostenido - y probado- que en poesía la semejanza de los componentes actualizados en un determinado nivel discursivo se sobrepone a la organización sintagmática del mismo y que, en esa clase de mensajes verbales, "la equivalencia es promovida al rango constitutivo de la secuencia", de manera tal que no sólo la iteración de unidades fónicas o léxicas da lugar a construcciones paralelísticas, también las figuras gramaticales (ya sea que se trate de morfemas o de matrices sintácticas) contraen relaciones de equivalencia (por semejanza o por oposición), al grado de que tal especie de paralelismos, no menos que el generado por la interacción de los niveles fónico y léxico, constituyen una de las bases estructurales del texto poético, pues tales fenómenos del plano de la expresión determinan una "reevaluación integral del discurso y de todos sus elementos, cualquiera que sea la naturaleza de éstos".

En consecuencia, los paralelismos gramaticales no deben ser atendidos únicamente clesde el punto de vista de la oposición de las llamadas "estructuras de frase" (que pertenecen a la significancia semiótica, o del sistema de lengua, como la ha definido Benveniste) con las "frases particulares" (que son parte de la significancia semántica o del universo del discurso), puesto que los parallelismus membrorum rebasan el nivel de la sobreimposición de las figuras "geométricas" de la articulación gramatical y del mero establecimiento de las "semejanzas verticales" y las "semejanzas horizontales" en un texto determinado e interactúan con las figuras producidas en los demás niveles.

Las relaciones contraídas entre los membra iniciales, centrales y terminales de un texto poético, no solamente muestran una configuración "arquitectónica" del texto en cuestión, sino que permiten al lector atento percibir las correlaciones homológicas pertinentes entre las estructuras semióticas y las estructuras semánticas. Jakobson ha insistido también en el hecho de que toda equivalencia fónica "proyectada sobre la secuencia [...] implica inevitablemente la 
equivalencia semántica"; del mismo modo, y por las mismas razones, las equivalencias gramaticales producen efectos semánticos secundarios en correlación con los efectos de sentido generados en el nivel de las articulaciones léxico-sintagmáticas.

A ese efecto de sentido de las "figuras gramaticales" parece haber aludido Jakobson cuando, al tratar de un canto checo de principios del siglo xIv, el Zisskiana cantio, no se redujo a comparar "las funciones de la gramática en poesía $y$ las relaciones geométricas en la pintura", sino que subrayó la necesidad de investigar la manera en la cual la combinación de procedimientos gramaticales hizo posible que "el placer poético, comunicado por las estructuras verbales convenientemente proporcionadas, se trocara en un poder de mando que conduce a una acción directa", o, si se prefiere decirlo con otras palabras, pasara de los efectos estéticos del texto a los efectos pragmáticos sobre los destinatarios.

Por lo que a este trabajo se refiere, nos proponemos atender específicamente a la semantización de las figuras gramaticales en ciertos textos de Jorge Luis Borges (los sonetos del "Ajedrez") y dejaremos de considerar las respuestas particulares que dichos textos pueden suscitar en cada uno de sus lectores; quiere decirse, por lo tanto, que tomaremos nuestro análisis, no como un comportamiento idiosincrático, sino como un comportamiento general o susceptible de generalización.

3. Sin embargo, antes de entrar en el texto de Borges, conviene decir algo más acerca del fenómeno al que queremos aludir por medio del término semanlización; esto es, acerca de aquella capacidad que poseen tanto los componentes mínimos del signo (los fonemas) como los signos llamados sincategoremáticos (los morfemas gramaticales) y las matrices sintácticas del sistema de la lengua natural para "impregnarse" de valores semánticos, valores que se establecen en correlación con los componentes de los demás niveles discursivos en aquella clase de textos construidos conforme al principio del paralelismo."

3 Cf. J. Pascual Buxó, "La semantización discursiva de las componentes mínimas del signo", Semiosis 6, 1981. 
Iurì Lotman, quien en su Estructura del texto artistico reelaboró algunos de los postulados de Jakobson; ha sostenido que la obra de arte verbal "posee su propio lenguaje, que no coincide con la lengua natural, sino que se superpone a ella"," de modo que el texto literario manifiesta un sistema semiótico particular dotado de sus propios signos y reglas de combinación que le permiten trasmitir una cierta clase de informaciones que no resultan trasmisibles por otros medios. Este "sistema modelizante secundario", al utilizar la lengua natural como materia prima, determina un diferente funcionamiento de los signos de ésta, en la medida en que suspende su carácter simbólico convencional y les concede un carácter icónico.

Los signos icónicos [dice Lotman] están constituidos de acuerdo con el principio de una relación de clependencia entre la expresión $y$ el contenido [...] Se comprende que, en estas condiciones, se produzca en el texto artístico la semantización de los elementos extra-semánticos (sintácticos) de la lengua natural. En lugar de una delimitación neta de los elementos semánticos, se produce un entrecruzamiento complejo: un elemento sintagmático de un nivel de la jerarquía del texto artistico se semantiza a otro nivel.

De ahí que para Lotman todos los elementos de un texto artístico sean "elementos semánticos" y que, en consecuencia, el concepto de texto sea idéntico al concepto de signo; si bien ello no implique, por supuesto, que siendo el texto literario un solo signo, no continúe siendo un texto (una secuencia articulada de signos). Así, el texto "conserva la división en palabras-signos del sistema lịngüístico general", pero por causa de la "simultánea transformación de los sig-. nos lingüísticos generales en elementos del signo artístico, se desarrolla un proceso inverso: la semantización de los elementos del sistema de la lengua natural (los fonemas $y$. los morfemas) que, "insertos en repeticiones conformes", se convierten en signos ellos mismos.

4 Iouri Lotman, La structure du signe artistique, Paris, Gallimard, 1979. 
Examinemos brevemente este punto de particular importancia: el concepto lotmaniano de la iconicidad del signo artístico. Como es bien sabido, Charles Sanders Peirce, en su clasificación de los signos, definió el icono como un signo o Representamen que "puede representar a su objeto predominantemente por su similaridad, con prescindencia de su modo de ser"; y dentro de los iconos distinguió las imágenes, que comparten cualidades simples con su objeto; los diagramas, que representan las relaciones análogas entre sus propias partes y las partes del objeto, y las metáforas que "representan el carácter representativo de un Representamen representando un paralelismo con alguna otra cosa". La diferencia entre una imagen y un diagrama respecto de una metáfora se halla en que esta última no representa una conexión con el "modo de ser" del objeto, sino un paralelismo entre el modo de representar de dos símbolos (es decir, de dos palabras, de dos sintagmas, etcétera), aun cuando cada uno de ellos sea Representamen de distintos objetos o, para decirlo con el propio Peirce, "aun cuando no hubiese parecido sensorial entre él y su objeto, y hubiera solamente una analogía entre las respectivas relaciones de las partes de cada uno"; de modo, pues, en un icono metafórico instituye una relación entre dos símbolos cuya analogía en aspectos de sus respectivos objetos o contenidos semánticos, representa un paralelismo con otro objeto que no es incluido en los designata de los signos separadamente considerados.

Se comprenderá así que, al estudiar las conexiones de la Iengua con otros sistemas de comunicación, Jakobson haya postulado entre signans y signatum (entre Representamen y Objeto) un tipo de relación icónica ya no fundada en la "similaridad efectiva", sino en la "similaridad asignada", es decir, una relación doblemente mediatizada entre signo y objeto, relación que se establece con base en la analogía estructural del contenido de clos signos y no en una analogía efectiva (sensible) entre las partes de un signo y las

5 Charles Sanders Peirce, La ciencia de la semiótica, Buenos Aires, Nueva Visión, 1974. 
partes de su objeto, como ocurre en las imágenes $y$-parcialmente- en los diagramas.

Habida cuenta de lo dicho, podremos postular que el carácter icónico atribuido por Lotman al signo artístico es el que corresponde a una metáfora (en el sentido de Pẹirce) o a una semejanza icónica asignada (en el sentido de Jakobson), de suerte que -en nuestro modo particular de ver- el sistema modelizante secundario de texto artístico resulta de

a) la relación icónica instaurada entre signos de una jerarquía lingüística dada, relación que descubre como su objeto o designatum una entidad formalizada por otra jerarquía semiótica de una comunidad cultural, de la que el sistema lingüístico constituye sólo uno de sus posibles interpretantes, y

b) que esa relación icónica entre dos signos de un sistema modelizante primario (una lengua natural) al instaurar un paralelismo o analogia entre las respectivas relaciones de cada signo con su objeto particular, representa un paralelismo con un objeto que no es el designatum de ninguno de los signos que contraen la relación icónica, sino un tercer objeto susceptible de ser representado metafóricamente, $i$. e., mediante una representación del modo de representar de otro signo.

Dicho diversamente, y adecuando nuestra definición a la terminología de Lotman, un signo del sistema lingüístico general $\left(\mathrm{S}_{1}\right)$, al ser utilizado como base del sistema modelizante secundario, establece una relación icónica con un signo de este segundo sistema $\left(\mathrm{S}_{2}\right)$, relación que representa a un objeto (designable como $S_{3}$ ) que, a su vez, forma parte de otro u otros sistemas de una comunidad cultural. La interacción de estos tres signos pertenecientes a tres jerarquías diferentes dentro de un mismo proceso de lengua, instaura lo que Lotman ha llamado el "núcleo semántico común a los diferentes sistemas" que se intersecan en el texto artístico; ese "núcleo" que es "percibido como la significación" del texto, permite "la salida de los límites de las 
estructuras de signos al mundo de los objetos", los cuales -no está por demás señalarlo desde ahora- deberán seguir siendo modelados conforme a sucesivas transcodificaciones.

Podemos retomar ya nuestra anterior definición del carácter "ficticio" o "autónomo" del texto artistico, diciendo que lo que antes designamos como una homología entre las sustancias reales concretas y su representación semiótica (lingüistica) es consecuencia del carácter icónico-metafórico que adquieren los signos del sistema lingüístico general al ser remodelados por el sistema retórico-literario, cuyo procedimiento invariante básico es el paralelismo, según lo ha descrito Jakobson.

Habida cuenta de todo ello, será posible definir el fenómeno de la semantización de las unidades inferiores de la lengua natural (fonemas y morfemas) y de las "estructuras de frase", como los efectos de significación homológica de los signos icónico-metafóricos, por cuyo intermedio el contenido de los textos artísticos se estructura en diversos niveles o instancias. Así, al quedar instaurada una relación icónica entre dos símbolos o unidades lingüísticas (o entre segmentos del signo total que es la obra de arte) las equivalencias entre las partes de éstos representan un paralelismo con "relación a alguna otra cosa" (Peirce), siendo esta "otra cosa" el "núcleo semántico común a los diferentes sistemas" (Lotman) que interaccionan en el texto. De ahi que, para decirlo con palabras de Lotman, "Ia equivalencia de elementos no equivalentes obliga a suponer que los signos que poseen diversos referentes en el nivel lingüístico, en el nivel del sistema secundario poseen un referente común".

4. Al frente de su libro de poemas El otro, el mismo, Borges inscribió una imposible dedicatoria al difunto Leopoldo Lugones:

Cambiamos unas cuantas palabras y le doy este libro $[\ldots]$ Ello no ocurrió nunca, pero esta vez. usted vuelve las páginas y lee con aprobación algún verso, acaso porque en él ha reconocido su propia voz $[\ldots]$ Mi vanidad y mi nostalgia han armado una escena imposible. Así será (me digo), pero mañana yo también habré muerto y se confundirán nuestros 
tiempos y la cronología se perclerá en un orbe de simbolos y de algún modo será justo afirmar que yo le he traído este libro y que usted lo ha aceptado.

Lo que el tiempo borra y confunde -podría haber escrito Borges- lo reinstauran los signos, que también son del tiempo, pero a los que el tiempo concede una fugacidad menos urgente. Asi, la "música" o el "rumor", esto es, los signos que de algún modo retienen los irreparables "días del hombre", rescatan al hombre del "ultraje" del tiempo. Pero no sólo las palabras de la poesía "transforman las penas verdaderas" en una especie de señales permanentes, también los objetos del mundo (el río, el sueño, o los nombres que apresan ese sueño y ese río) son parte de una jerarquía de símbolos: su sola presencia nos los muestra como elementos de un lenguaje más vasto y éficaz; los objetos son también signos que se representan a sí mismos $y$, además, símbolos con los que podemos representar otros objetos. Nombres y cosas son "el otro" y "el mismo":

Todas las cosas son palabras del Idioma en que Alguien o Algo, noche y dia, Escribe esa infinita algarabia

Que es la historia del mundo...,

escribió Borges en "Una brújula", y este modo de ver las cosas como signos o símbolos de otras cosas y de otros signos es el único medio de que el hombre dispone para nombrar lo "innombrable". Aquello que lo trasciende y domina, que lo insçribe en esa trama "de polvo y tiempo y sueño $y$ agonías" que es su vida, repetida por cada uno y por los demás, hasta convertirlos a todos en signos temporales del tiempo. La imposible permanencia de "el mismo". podrá ser. recuperada en la de "el otro" y la menguada concreción de un objeto (de la misma palabra que es lo que nombra y también lo que no nombra) podrá abarcar -expresar-. la trama entera del universo.

6 Jorge Luis Borges, Obra poética, Buenos Aircs, Emecé, 1968 (S? ed.). 

Así lo dijo Borges en "El Aleph":

vi una pequeña esfera tornasolada, de casi inalterable fulgor. Al principio la vi giratoria; luego comprendi que ese movimiento era una ilusión producida por los vertiginosos espectáculos que encerraba. Cada cosa (la luna del espejo, digamos) era infinitas cosas, porque yo claramente las veía desde todos los puntos del universo [...],

y así habremos de entenderlo nosotros por lo que toca a la escritura borgesiana y a su tema primordial: la inmóvil sucesión del tiempo y la permutabilidad de objetos y palabras, de símbolos y cosas.

"Ajedrez" - título de dos sonetos incluidos en El olro, el mismo- constituye, a nuestro modo de ver, otras tantas variaciones de lo que el mismo Borges hubiera podido llamar la trama "del tiempo y del destino" o, mejor, de la materia deleznable $y$ sin embargo imperecedera de que están construidos. Dice así el primer soneto de

Ajedrez

En su grave rincón, los jugadores

Rigen las lentas piezas. El tablero

Los demora hasta el alba en su severo

Ambito en que se odian dos colores:

Adentro irradian mátgicos rigores

Lats Cormas: torre homérica, ligero

Caballo, armada reina, rey postrero,

Oblicuo alfil y peones agresores.

Cuando los jugadores se hayan ido, Cuando el tiempo los haya consumido, Ciertamente no habrá cesado el rito.

En el oriente se encendió esta guerra Cuyo anfiteatro es hoy toda la tierra. Como el otro, este juego es infinito.

Ya hemos dicho que las formas gramaticales del sistema 
de la lengua natural, y que carecen en ella de significación semántica, en cuanto aparecen actualizadas en las "regularidades conformes" del sistema modelizante secundario, manifiestan contenidos semánticos equivalentes con los manifestados por los componente léxicos del texto en cuestión. Dicho aun de otra manera, que por medio del "parallelismus membrorum" no sólo se actualizan valores gramaticales (o "relacionales") del sistema lingüístico interpretante, sino que tales "figuras", al contribuir al establecimiento de expresas relaciones de equivalencia de los "conceptos materiales" de dicho sistema, quedan instauradas como signos del sistema modelizante secundario que rige la significancia semántica del texto; en breve, del paradigma o paradigmas ideológicos que subyacen en el proceso de transcodificación que determinan -en última instancia - su sentido global. Este senticlo "nuclear" o último no puede serle asignado de antemano a ningún texto; es, por el contrario, resultado de una serie de sincretismos que interesan a todos sus niveles y que sólo podrá ser cabalmente deducido en cuanto se haya completado el análisis del mismo y de sus contextos ideológicos más amplios. En nuestro caso concreto, algunas de las citas de Borges transcritas más arriba - y otras a la que después acudiremos - nos permitirán orientarnos hacia ese sentido "nuclear" del soneto que nos ocupa.

El primer cuarteto de "Ajedrez" I consta de dos oraciones (una simple y otra compuesta); esquematizaremos su estructura en el siguiente cuadro:

1. En su grave rincón $\rightarrow$ los jugadores $\rightarrow$ (c.c.) (sujeto anim.)

2. rigen $\rightarrow$ las lentas piczas // El tablero $\rightarrow$ (verbo act.) (c.d.inan.) (sujeto inan.) trans. pres. indic.)

3. los [jugadores] $\rightarrow$ demora $\rightarrow$ hasta el alba $\rightarrow$ (c.d.anim.) (verbo act. trans. pres. indic.) 
4. en su severo ámbito $\rightarrow$ en que se odian $\rightarrow$ dos colores. (c.c.)

(verbo act. reflex. pres. indic.) (sujeto inan.)

En la primera oración, el sujeto es animado (los jugadores), en tanto que en la segunda es inanimado (el tablero); en ambas el verbo es activo transitivo y conjugado en presente de indicativo, pero el complemento directo u objeto del primero (rigen) es un sustantivo inanimado en plural (las lentas piezas), mientras que el objeto del verbo principal de la segunda oración (demora) tiene por objeto directo un pronombre (los) que se refiere a jugadores, sustantivo animado. Ambas oraciones poseen un complemento circunstancial, de lugar, en la primera (en su grave rincón); de tiempo en la segunda (hasta el alba); pero en tanto que el complemento circunstancial de la primera oración es por relación al verbo, el de la segunda es por atribución.

Este sumario análisis gramatical diría muy poco respecto del texto de Borges si no fuese por el hecho de que nos permite asentar ciertas correlaciones que en él se establecen entre el nivel de los "conceptos relacionales" y el de los "conceptos materiales". En efecto, el hecho de ser sustantivos animados o inanimados diferencia a los sujetos de una y otra oración, pero la circunstancia de que el sujeto de la segunda (tablero) sea una metonimia del objeto directo de la primera (las piezas) los hace semánticamente equivalentes; equivalencia que, por otro lado, aparece actualizada entre el sujeto de la primera oración (los jugadores) y el objeto de la segunda (los [jugadores]), de modo que dos componentes léxicos semánticamente equivalentes han invertido sus funciones gramaticales en una y otra oración, dando así origen a una estructura quiasmática que puede ser representada por medio del diagrama de la página 66 .

$\mathrm{Si}$ atendemos ahora a la proposición subordinada de la segunda oración, advertiremos que el verbo transitivo de aquella, ya no es activo, sino reflexivo (se odian), es decir, que determina la coincidencia entre el sujeto y el objeto 


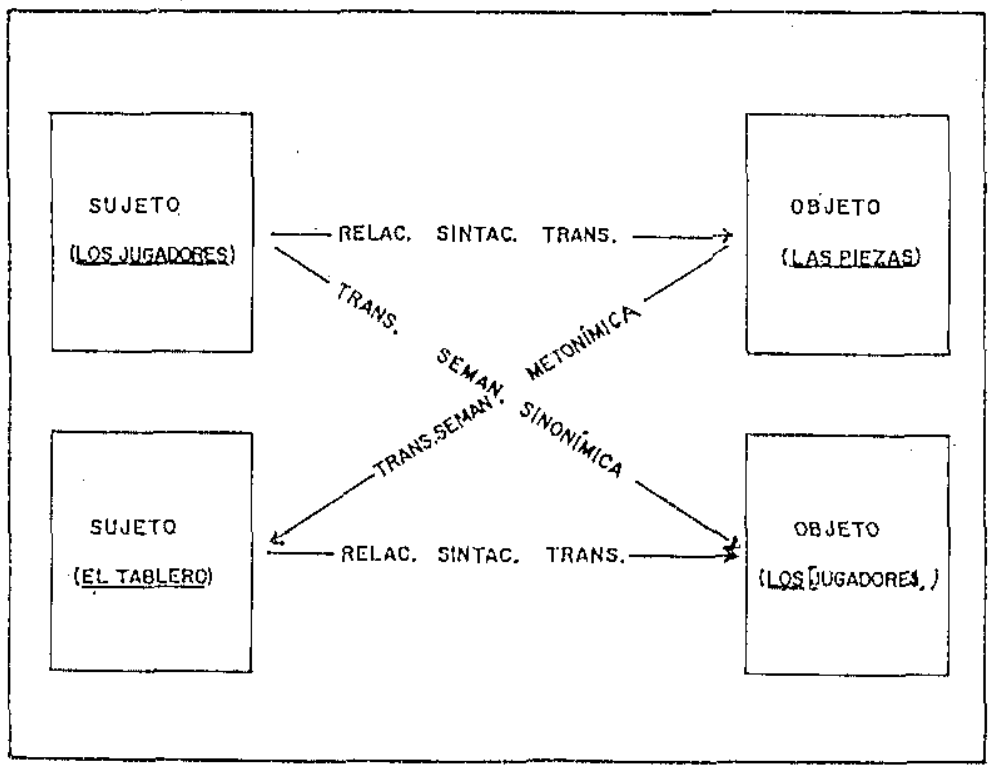

de la misma acción. Por medio de dos colores se establecen, en. efecto, tres pares equivalentes: jugadores $=$ piezas, $t a$ blero $=$ piezas, jugadores $=$ tablero, en cuanto que los dos coloress, además de sujeto y objeto en la oración reflexiva, constituyen aspectos de la sustancia de la expresión de piczas y de tablero y, por lo tanto, deben ser considerados como signos icónicos de los conjuntos opuestos en el juego del ajedrez $y^{r}$, consecuentemente, como metáfora de los juigadores.

De ahí que el sujeto-objeto plural del verbo reflexivo se odian proporcione, por causa de su misma función gramatical, una reiterada información sobre el fenómeno de la reversibilidad de los sujetos y los objetos en esa primera estrofa del soneto de Borges. De conformidad con todo lo cual el esquema anterior debe ser ampliado de la manera que se muestra en el diagrama de la página 67.

No es menos significativo que en el primer cuarteto sólo los sustantivos que funcionan como complementos (objeti- 


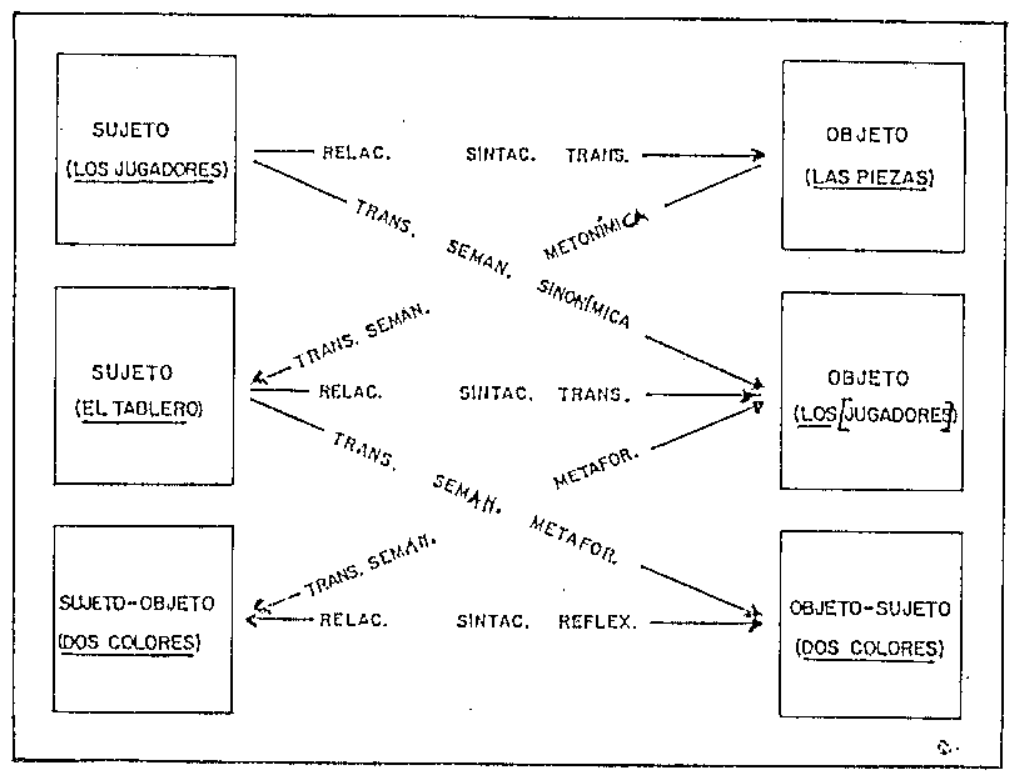

vo o circunstancial) aparezcan modificados por epítetos: grave rincón, lentas piezas, severo ámbito; en tanto que los sustantivos sujeto aparecen sin modificación alguna, es decir, que las unidades léxicas que designan el espacio o "ámbito" donde ejercen sus acciones los sujetos oracionales están todas articuladas con epítetos semánticamente equivalentes (por cuanto que todos ellos son susceptibles de ser incluidos en el complejo, conceptual de lo "rigurosamente meditado o mediatizado"); pero, por otra parte, todos esos epítetos constituyen casos de hipálage, que verifican el desplazamiento de un adjetivo -que semánticamente corresponde al sustantivo sujeto de cada oración- para articularlo con un sustantivo complemento. En efecto, tanto grave como lento son propiedades atribuibles rectamente a los jugadores y no al rincón o a las piezas; esto es, a las acciones de los sujetos y no a las propiedades del espacio en que éstos se recluyen ni a los objetos que "rigen"; severo corres- 
ponde semánticamente al sujeto "juego" (designado por la metonimia de tablero) y no a su espacio lísico (ámbito) ni a los jugadores-objeto "demorados" por el tablero-juego. Con todo lo cual toma a actualizarse en el texto borgesiano la semantización de las "figuras gramaticales" relativas a la complementación adnominal.

En oposición a la primera estrofa -que consta de dos oraciones-, la segunda sólo tiene una; pero si en la primera cada sustantivo sujeto (jugadores, lablero, colores) era regido por su propio verbo (rigen, demora, se odian), en la segunda un solo verbo (irrudian) rige a un sujeto plural (las formas) que se multiplica en una enumeración de miembros sinonímicos por medio de la aposición al sustantivo genérico formas de los específicos: torre, caballo, reina, rey, alfil y peonés. Así, el objeto genérico de la primera oración del primer cuarteto (las piezas) pasa a ser el sujeto múltiple de la única oración de la segunda estrofa, cada una de cuyas denominaciones aparece articulada con un epiteto simétrico: torre homérica, ligero caballo, armada reina, rey postrero, oblicuo alfil y peones agresores.

Por otro lado, si tomamos en cuenta que el segundo cuarteto se inicia con un adverbio anafórico (adentro) que remite al conjunto trimembre jugadores-lablero-colores (integrado por los tres sujetos de la primera estrofa), al queclar ambas estrofas semánticamente vinculadas por medio de la anáfora, se constituye un nuevo paradigma trimembre, cuyos componentes correlativos son: piezas-formas-rigores, i. e., una serie en la cual el objeto piczas pasa de ser denominado por medio de las representaciones icónicas de cada una de sus figuras (lorre, caballo, reina...) a ser designado metafóricamente, esto es, aludiendo tanto a su forma de expresión como a su función en el juego $y$, en consecuencia, al riguroso código que lo rige. (Veremos luego cómo esos dos' paradigmas textuales permiten la aparición de un tercer conjunto trimembre: juego-rito-guerra que, a nuestro parecer, revela una de las claves semántico-ideológicas del poema.)

Detengámonos, sin embargo, en otras peculiaridades de 
la segunda estrofa que pueden sernos útiles para precisar lo que hasta ahora llevamos dicho; concretamente sobre el verbo irradian (cuyo contenido semántico central puede ser definido como "emisión de rayos de luz o energía") $y$ ' su complemento mágicos rigores (a los que provisionalmente podemos dar el significado de "ley'es ignotas"). Consecuentemente, las piezas se representan a sí mismas - como figuras emblemáticas $y$ como valores del ajedrez- pero, al mismo tiempo, se "proyectan" sobre otra "cosa" para significarla. Con todo, en ese segundo cuarteto de "Ajedrez", la posición hiperbática de formas (sujeto gramatical pospuesto a la actualización del complemento directo mágicos rigores) y la enumeración de las formas sinonímicas del sujeto (torre, caballo, reina...), pospuestos a la enunciación del complemento del verbo irradian, provoca un ambigitedad semántica: las formas sujeto son, al mismo tiempo, los mágicos rigores que ellas mismas "irradian", ambigüedad que, por lo demás, halla sustento en la reversibilidad de los sujetos y los objetos gramaticales de la que ya dimos cuenta al analizar la primera estrofa.

Importa subrayar cómo a partir del subsistema semántico instaurado por los epítetos de la segunda estrofa se desarrolla, en correspondencia con la primera, una secuencia de hipálages que, sin embargo, no son de la misma clase semántica que la de los epítetos del primer cuarteto. En efecto, si en éste los adjetivos que atribuyen propiedades a los sustantivos núcleos de los complementos pueden ser considerados como un desplazamiento de cualidades entre los sujetos gramaticales y sus objetos, aquí —en la segunda estrofa- los epítetos se hallan en correlación con valores formalizados por otro sistema: el del "juego" de la vida social. No podemos referirnos ahora al carácter emblemático de las figuras del ajedrez, pero es evidente que, en su conjunto, representan un modelo ancestral del mundo según el cual ta sociedad humana -en correspondencia con la estructura del mundo celeste- se articula en tres grupos netamente delimitados 
en sus funciones: los guerreros, los sacerdotes y los pastores. ${ }^{7}$

En relación con nuestro propósito, sólo interesa señalar el clesdoblamiento referencial de los epítetos que, en la segunda estrofa cle "Ajedrez" I, al igual que en la primera de "Ajedrez" II, manifiestan el carácter ambiguo (la polivalencia semántica) del juego y de sus elementos o, si se prefiere decirlo con otros términos, su condición de iconos metafóricos a los que les es dable representar, al mismo tiempo que "esta" realidad del sistema del ajedrez, "otra" u otras realidades a las que el juego puede ser homologado; es decir, un modelo del mundo que se estructura como un juego regido por leyes a la vez inflexibles e ignotas; modelo lógico del texto de Borges.

El primer terceto de "Ajedrez" I consta de una oración compuesta cuyas oraciones subordinadas, antepuestas a la oración principal, ocupan con perfecta simetría morfológica los dos primeros versos de la estrofa, quedando la oración subordinante en el último verso:

Cuando los jugadores se hayan ido, Cuando el tiempo los haya consumido, Giertamente no habrá cesado el rito.

Al estricto paralelismo morfológico y versal de las dos proposiciones subordinadas (introducidas ambas por el adverbio temporal cuando que, además, funciona como nexo anafórico respecto de sus antecedentes de las estrofas anteriores) corresponde la marcada oposición funcional de sus componentes gramaticales. En la primera, el verbo activo reflexivo reitera el carácter de sujeto y objeto que desempeñan, simultáneamente, los jugadores, situación análoga a la que les correspondía en el último verso de la primera estrofa; pero en la segunda subordinada de este primer terceto, los jugadores ya no son sujeto y objeto de su propia

7 Cf. Georges Dumézil, Los dioses de los indoeuropeos, Barcelona, Seix Barral, 1970. 
acción, sino únicamente objeto directo de la acción del sujeto tiempo, enunciada por un verbo activo transitivo: los haya consumido.

Refuerzan aún más la semantización de las figuras gramaticales de este texto de Borges las equivalencias contraidas por los verbos de Jas tres oraciones que componen el primer terceto. En todas ellas, los verbos aparecen conjugados en tiempos perfectos; pero si en las oraciones subordinadas los verbos están en pretérito perfecto de subjuntivo - por cuyo medio se expresa una acción concluida en un pasado relativo, es decir, determinado por una acción efectiva enunciada en indicativo-., el verbo de la oración subordinante, precisamente en futuro perfecto de indicativo, afirma - al negar su contingencia-- el carácter permanente del juegorito. Queda así establecida la equivalencia de "este" rito incesante.

La transformación metafórica del juego en rito, ya preanunciada por los "mágicos rigores" que "irradiaban" las piezas-formas del ajedrez en el segundo cuarteto, hace posible la instauración del tercer paradigma léxico al que ya hicimos referencia y que nos permitirá formular —en cuanto atendamos a la última estrofa del soneto- ese "núcleo" semántico que, al decir de Lotman, permite salir de los "límites de las estructuras de signos" y llegar al mundo de los "objetos" o, mejor, al modelo o modelos del mundo que subyacen en cada texto y determinan su organización semántico-ideológica. Recordemos lo que dice e! terceto final de "Ajedrez" I:

En el oriente se encendió esta guerra

Cuyo anfiteatro es hoy toda la tierra.

Como el otro, este juego es infinito.

Ahí, la dualidad juego-rilo fundada en el tercerto anterior, aparece completada por el último miembro de un nuevo paradigma trimembre: guerra, término que, además, engloba e identifica a los dos paradigmas léxicos antes mencionados: jugadores-lablero-piezas; piezas-formas-rigores. En efecto, en la primera estrofa de "Ajedrez" II, el juego, de- 
signado mediante la enumeración de las piezas que lo componen, es presentado como una "batalla", y en el primer terceto de ese soneto, el jugador se hace equivalente a las piezas por cuanto es "prisionero... de otro tablero de negras noches y de blancos días". También ahí se establece una correlación homológica entre sujeto y objeto gramaticales: las piezas y los jugadores, cuyas respectivas oposiciones "sobre lo negro y blanco del camino" están gobernadas por una voluntad que los trasciende: el "rigor adamantino/ [que] sujeta su albeclrío y su jomada". Pero también sobre еsa voluntad que "mueve" al jugador y a "la pieza", se instala un poder supremo y desconocido, de suerte que tanto el destino del juego (dle cada juego), del hombre (de cada hombre), y del mismo "rigor adamantino" que sujeta el juego y la vida, sólo son expresiones de un clios desconocido:

Dios mueve al jugador, y ćste, la picza.

¿Qué clios cletrás de Dios la trama empicza

De polvo $y$ ticmpo $y$ sueño $y$ agonias?

Tanto "Ajedrez" I como "Ajedrez" II descubren, pues, un núcleo semántico-ideológico común y en el cual recalan torlas las microestructuras semánticas de ambos textos: el modelo cabalístico del mundo según el cual el universo es regido por un ser misterioso de cuya actividad sólo puede hablarse por medio de metáforas. Tal como enseñan las doctrinas del Zóhar, existen tres (o más) mundos homólogos sobre los que actúa ese principio dominante (el En-Sof); uno de esos mundos, aquel que se encuentra en relación directa con el En-Sof, es inaccesible a la experiencia humana y, en consecuencia, totalmente innombrable. El otro, colocado debajo del primero, resulta accesible y permite al hombre el conocimiento de Dios bajo el aspecto de sus atributos. De hecho, ambos mundos no son más que uno sólo, "el otro" es un reflejo de "el mismo", aunque ese En-Sof únicamente pueda ser nombrado -i.e. conocido- por medio de los nombres de sus "refiejos" en "el otro".

La cábala - ha clicho Borges en la penúltima de sus Siete 
noches- no es sólo una pieza de museo, es un sistema que "puede servirnos para pensar, para tratar de comprender el universo". Según esta doctrina gnóstica

el univcrso es obra de una Deidad deficiente [...] Es decir, de un Dios que no es al Dios. De un Dios que desciende lejanamente de Dios [...] ¿Por qué crea este mundo tan leno de errores, tan Ileno de dolor físico...? Porque la Divinidad ha ido disminuyéndose y al Ilegar a Jehová crea este mundo falible:

Así, pues, ese "núcleo semántico" al que remiten los signos del sistema lingüístico general, en cuanto hayan sido sometidos a las transcodificaciones efecuuadas a partir del sistema modelizante retórico-literario se halla - - a su vezregido por un tercer sistema de carácter ideológico a partir del cual los "objetos del mundo" adquieren una particular organización jerárquica; esto es, se articulan en un modelo formal de la realidad, cuya expresión ha de seguir - en todos los casos - amoldándose a las determinaciones de un sistema interpretante primario.

Con todo, el sistema o conjunto de sistemas de ese tercer nivel de modelación del texto, es recuperable en la medida en que a la experiencia individual se sobreponga la experiencia comunitaria, quiero decir, la acción de un sistema traslingüístico -ideológico- por cuyo medio los "objetos del mundo" ya no se perciben como signos de un sistema semiótico, sino como entidades "naturales", que, por ello mismo, parecen no deber su "imposible existencia" a ningún sistema formal.

5. Sintetizando lo expuesto, diremos que el soneto de Borges -cualquier texto literario- se constituye en las siguientes instancias o planos de interacción semiótico-semántica:

a) una lengua general cuyas formas (unidades lingüisti-

8 Jorge Luis Borges, Siete noches, Mexico, Fondo de Cultura Económica, 1980, p. 134. 
cas, matrices de combinación, etcétera) son utilizadas como base de expresión por parte de

b) un sistema modelizante secundario (un sistema retórico de transcodificación) por obra del cual los signos del primer sistema suspenden su función simbólico-denotativa para asumir una función icónico-metafórica; esto es, el carácter de representaciones semióticas de otra clase de representaciones semánticas. En este segundo nivel de estructuración aparecen las marcas de semantización de las uniclades mínimas y de las reglas de combinación del primer sistema modelizante, así como la construcción de los paradigmas léxicos particulares de cada texto.

La relación de $a$ y de $b$, que determina una primera equivalencia entre el funcionamiento (o modo de significar) del sistema global y del sistema modelizante secundario, se constituye como interpretante de un tercer sistema modelizante $c$, a cuyo cargo corre proporcionar un modelo del mundo, i. e., la organización de los dominios de la experiencia de una comunidad social. Este tercer sistema ideológico, representado por medio de las equivalencias instauradas en la actualización concreta de miembros de a transcodificados por $b$, constituye el "núcleo semántico común" que determina, en última instancia, el sentido del texto o la macroestructura semántica del mismo. Aislar dicho núcleo es la meta última del análisis textual, aunque no necesariamente el punto de arribo de las sucesivas "lecturas" del texto. Está claro que la interacción de $a$ y de $b$ puede dar origen a otra clase de enucleaciones del sentido, vale decir, de interpretaciones idiosincráticas superponibles, ya que -como observó Jakobson- las palabras "conservan el mismo significado general a través de la diversidad de los usos" $y$, por lo tanto, cada lector puede privilegiar uno solo de los niveles articulatorios del texto artístico en su proceso de descodificación.

No podemos entrar ya en la consideración de los sentidos que cada lector "descubre" en un determinado texto, puesto que ello implicaría hacerse cargo, no sólo de la presunta naturaleza textual de las respuestas idiosincráticas (respuestas que, en términos generales, aparecen como una actividad 
LAS ARTICULACIONES SEMÁN'TICAS DEL TEX'TO LITERARIO 75 amorfa, es decir, pre-semiótica), sino pasar al terreno de las teorías de la recepción y de las "prácticas significantes", que no son materia de este ensayo.

José Pascual Buxó

Seminario de Poética

Instituto de Investigaciones Filológicas 